\title{
Mulheres na aviação: menos pose, mais ação
}

\section{Women in aviation: less posing, more action}

\author{
Patrícia Almeida de Rezende1, Thainá Marinho da Silveira²
}

1 Mestre em Linguística Aplicada. Técnica Administrativa na Agência Nacional de Aviação Civil (ANAC), Rio de Janeiro, RJ, Brasil. parezende@gmail.com

2 Estagiária na na Agência Nacional de Aviação Civil (ANAC), Rio de Janeiro, RJ, Brasil. thaina.silveira@anac.gov.br

\begin{abstract}
RESUMO
Apesar da participação crescente da força de trabalho feminina na aviação, a representação midiática da mulher nessa área é tendenciosa e utiliza-se de uma linguagem carregada de estereótipos. No presente trabalho são demonstrados alguns recursos imagéticos e linguísticos de manutenção desses estigmas sociais. Os resultados deste estudo evidenciam o uso de uma linguagem que reforça a assimetria na participação de homens e mulheres no mercado de trabalho e favorece determinado perfil profissional em detrimento de outros, bem como de imagens não condizentes com a situação real da mulher atuante na indústria aeronáutica nos tempos modernos.

PALAVRAS-CHAVE: Mulher na aviação; Imagens midiáticas; Linguagem e cultura
\end{abstract}

\section{ABSTRACT}

Despite the growing participation of the female labor force in aviation, the media representation of women in this area is biased and uses a language full of stereotypes. In this paper we demonstrate some imagistic and linguistic resources for maintaining those social stigmas. The results of this study suggest the use of a language that consolidates the asymmetry between men and women in the market and favors certain professional profile at the expense of others, as well as images which are not consistent with the real situation of women in the aeronautical industry nowadays.

KEYWORDS: Woman in aviation; Media images; Language and culture

Pontifical Catholic University of Rio Grande do Sul Porto Alegre, RS, Brazil

Editor

Thaís Russomano

Microgravity Center PUCRS, Brazil

Executive Editor

Rafael Reimann Baptista

Faculdade de Educação Física e Ciências do Desporto, PUCRS, Brazil

e-ISSN: 2179-703X
Corresponding Author:

Patrícia Almeida de Rezende

parezende@gmail.com

Received: September 11, 2014 Accepted: November 13, 2014

(C) 2014 EDIPUCRS 


\section{Introdução}

Sabe-se que nos últimos dez anos a mulher está cada vez mais presente no mercado de trabalho, tanto em países desenvolvidos como em desenvolvimento. Aparentemente, conforme assinala Probst (2003:1), o mundo anda apostando em profissionais do sexo feminino cujo perfil inclui a multifuncionalidade, a capacidade de trabalho em equipe, a persuasão e a cooperação. Hoje elas ocupam altos postos nas grandes empresas e até pilotam jatos, embora ainda haja desigualdade salarial entre homens e mulheres (Barboza, 2014: 62-63).

Segundo Probst (2003), apesar da participação feminina representar um número significativo no mercado, somente $24 \%$ das mulheres ocupam cargos superiores e recebem apenas $71 \%$ do salário dos homens. Parece que esse percentual geral de mulheres no mercado mantém-se em cada ambiente corporativo isoladamente. Por exemplo, de acordo com dados da Controladoria Geral da União ${ }^{1}$, cerca de $26 \%$ do total atual de cargos comissionados nas funções de assessor, gerente, diretor e demais funções de liderança da Agência Nacional de Aviação Civil (ANAC) são ocupados por mulheres. Se considerarmos apenas os concursados (situação ativo permanente), o percentual de mulheres nomeadas para cargos comissionados é ainda menor, em torno de $17 \%$. Um levantamento das nomeações divulgadas no Diário Oficial da União de janeiro de 2011 até agosto de $2014^{2}$ indica que o percentual total de mulheres nomeadas na ANAC nos últimos três anos está em torno de $28 \%$. Por conseguinte, qualquer que seja a instância considerada, vê-se que há um desequilíbrio no percentual de homens e mulheres em cargos de liderança.

De acordo com Abramo (2007:7), é fundamental desvendar os mecanismos que reproduzem essas desigualdades. A autora informa que, no Brasil, as mulheres representam mais de $40 \%$ da população economicamente ativa, são mais escolarizadas e têm participação maior que 50\% no mercado, embora persistam as desigualdades de rendimento por hora trabalhada em relação aos homens, principalmente nas faixas superiores de escolaridade(Abramo, 2007:6).

A despeito da participação maciça da mulher no mercado de trabalho, pelo menos no âmbito da aviação a mulher ainda tem muito o que conquistar. Conforme assinala Abramo (2007. p. 3), a situação da mulher

\footnotetext{
Dados obtidos pelas autoras deste artigo em agosto de 2014, em consulta ao Portal da Controladoria Geral da União.

2 Dados obtidos pelas autoras deste artigo em agosto de 2014, em consulta ao Portal da Imprensa Nacional.
}

como força de trabalho secundária presente no imaginário social, empresarial, sindical e da própria mulher, bem como na formulação das políticas públicas, constitui elemento de subordinação de gênero e não condiz com a realidade da presença feminina no mercado. Certamente a posição da mulher na aviação reflete a "subvaloração social e econômica do papel da mulher na sociedade", colocada nos termos de Abramo (2007:8).

Consta que a primeira mulher na história da aviação a receber licença para pilotar foi Raymond de Laroche, em 1910, tendo sido também a primeira mulher a fazer um voo solo, em Paris, no mesmo ano (Stochero, 2011). Mais tarde, a norte-americana Amélia Earhart aventurou-se a atravessar o oceano Atlântico em voo solo (Zwerdling, 2013). Desde então um número cada vez maior de mulheres vêm-se inserindo nos mais variados setores da aviação, inclusive como aviadoras no comando de aviões e helicópteros em todo o mundo.

\subsection{Mulher brasileira}

A entrada da mulher como piloto na aviação brasileira deu-se na década de 30. Entre as pioneiras da aviação no Brasil destacam-se a aviadora acrobata Joana Martins Castilho D'Alessandro (1924-1991), Thereza de Marzo (1903-1986), possivelmente a primeira a receber o brevê (licença e habilitação), em 1922, Anésia Pinheiro Machado (1904-1999), segunda a receber o brevê no mesmo ano, e Ada Leda Rogato (1910-1986), primeira mulher a obter licença como paraquedista, a pilotar um planador e a terceira a possuir o brevê em avião. Ada Rogato também se notabilizou por suas acrobacias aéreas e por ter sido a primeira piloto agrícola do País, bem como a primeira a cruzar a floresta amazônica em voo solo, num avião de pequeno porte, sem rádio (Rodrigues \& Lima, 2009; Zwerdling, 2013).

Em 2006, formou-se a primeira oficial aviadora na Força Aérea Brasileira (FAB). Atualmente a FAB conta com mais de 20 mulheres no comando de aeronaves, inclusive as de grande porte, que atuam principalmente no transporte de tropas e na busca e salvamento. Desde 2011 há relatos de voos comerciais pilotados por mulheres com uma tripulação inteiramente feminina no Brasil, constituída de piloto, copiloto, chefe de cabine e comissárias, conforme relatado por Stochero (2011). Esses voos, entretanto, apenas são reportados na mídia associados a ocasiões especiais, como o Dia Internacional da Mulher, como estratégia inovadora de marketing das companhias aéreas, dada a raridade com que ocorrem. 
Segundo divulgado por Peng (2010) e Stochero (2011), com base em dados do Portal de Transparência da ANAC, a cada ano aumenta consideravelmente a participação feminina na aviação. Em 2009 foram expedidas 44 licenças para pilotos do sexo feminino no Brasil, sendo 35 para piloto privado, oito para piloto comercial e uma para comandante de linha aérea o nível masl alto da carreira na aviação civil, para o qual são necessárias pelo menos 1.500 horas de voo (Stochero, 2011). No ano seguinte, esse número quadruplicou, tendo sido expedidas 193 licenças de piloto para mulheres: 51 de piloto privado, 65 de piloto comercial e 15 de piloto de linha aérea (Peng, 2010). Somem-se a essas, outras 32 licenças emitidas para mulheres pilotos de helicóptero em 2010 (Peng, 2010). A Polícia Militar atualmente conta com mais de 30 mulheres no comando de helicópteros, além das que cuidam de assuntos administrativos e atuam na assistência às operações de patrulha aérea e de resgate e salvamento (Ferro et al., 2013). Na visão de Stochero (2011), a tendência é que novos recordes sejam alcançados nos próximos anos.

Em princípio, nada impede que a mulher exerça qualquer atividade na aviação. De fato, tanto o conceito de mulher associado à fragilidade quanto os papéis sociais normalmente atribuídos à mulher vêm sendo questionados. Nesse sentido, Rodrigues (2005) destaca a noção de mulher para além do gênero, que implica o sujeito socialmente construído.A autora cita Butler (2003: 29), segundo a qual a noção de mulher está contextualizada em "conjuntos específicos de relações, cultural e historicamente convergentes". Judith Butler (apud Salih, 2013) apresenta análises teóricas sobre o sujeito e seus processos de formação e propõe um novo conceito de mulher, independente da biologia. Para Butler (apud Rodrigues, 2005), tal distinção resulta na constituição de uma identidade fixa, que impede de pensar e analisar a mulher em sua realidade.

Na opinião de Almeida (2002:93) a análise dos discursos contemporâneos em questões de gênero fornece subsídios para uma visão crítica, desestabilizadora e desconstrutora dos estereótipos dos papéis femininos da atualidade veiculados nas imagens e nos textos dos meios de comunicação. Com o propósito de questionar o posicionamento da mídia pela manipulação da imagem feminina, a autora descreve um estudo de caso e apresenta em seu artigo uma tradução de um conto de Margaret Atwood (1997)³:

\footnotetext{
Texto original: The Female Body has many uses. It's been used as a door knocker, a bottle opener... It sells cars, beer, shaving lotion, cigarettes, hard liquor; it sells diet plans and diamonds, and desire in tiny crystal bottles. Is this the face that launched a thousand products? (Atwood, 1997:35)
}

O Corpo Feminino tem muitos usos. Tem sido usado como aldrava, abridor de garrafa [...]. Vende carros, cerveja, loção de barbear, cigarros, bebidas alcoólicas; vende planos de dieta e diamantes, e desejos em pequenas garrafas de cristal. É essa a face que lançou mil produtos?

\subsection{Sobre as representações midiáticas}

Partindo do ponto de vista de que o discurso de estímulo ao consumo, ao mesmo tempo em que reflete os padrões de consenso, consolida os valores da modernidade-mundo, Trindade (2005:81-95) admite que a propaganda e a publicidade podem constituir-se em importantes instrumentos de inclusão ou exclusão social. Para tanto, conforme afirma o mesmo autor, a publicidade faz uso intencional da combinação de vários signos, verbais e não verbais (imagens), que contribuem, em última instância, para o processo de mundialização das culturas.

Em seu estudo sobre a função da fotografia na sociedade, Buitoni (2011) afirma que, no Brasil, desde os anos 1900 deu-se o início do casamento entre a fotografia e a mídia impressa com o lançamento da Revista da Semana no Rio de Janeiro. Segundo a autora, para entender como a fotografia transforma a cultura humana é preciso desenvolver uma forma de percepção que se denomina inteligência visual ou consciência imagética. Dulcilia Buitoni (2011:7-8) afirma que não existe imagem inocente, posto que a produção de visualidades é feita com o propósito de ser utilizada como instrumento de educação, arte e mudança social.

$\mathrm{Na}$ opinião de Buitoni (2011:164), pensamentos podem serinferidos por meio de expressões e posturas. As comunicações não verbais, como a expressão do rosto, gestos e postura, transparecem no corpo, bem como em artefatos associados ao corpo e na posição que a pessoa ocupa no espaço e seu entorno. Trindade (2005: 86-94), por sua vez, advoga que a mídia muitas vezes comunica-se por meio de simbolismos e que o entendimento dos simbolismos empregados na publicidade é essencial para que possam ser lançadas críticas à perversão do sistema. $\mathrm{O}$ autor pressupõe que o universo simbólico da publicidade inclui de praxe representações estereotipadas dos gêneros masculino e feminino feitas sob medida para o público-alvo idealizado. Dessa forma, o discurso midiático, por meio de artifícios visuais e verbais impactantes principalmente nos campos afetivo, estético e profissional, garante a adesão dos consumidores aos produtos e serviços.

Embora a fotografia pretenda retratar o real, Wilson \& Martelotta (2013:72-73) lembram que a fotografia de um indivíduo é apenas uma 
representação icônica desse indivíduo. Um ícone é um signo utilizado para designar algo que lhe seja semelhante em algum aspecto. A noção de signo implica que um elemento $\mathrm{A}$, de natureza diversa, funcione como um representante de um elemento $\mathrm{B}$, ou seja, o elemento A guia o comportamento dos indivíduos para um determinado fim de maneira semelhante ao modo como um elemento B os direcionaria para aquele mesmo fim.

\subsection{Sobre linguagem e ideologia}

Fiorin (2007:54) ressalta que a mesma realidade pode ser apreendida diversamente por pessoas distintas. $\mathrm{O}$ discurso, afinal, não reflete a representação exata do mundo, mas uma abstração ancorada na prática social. $\mathrm{O}$ autor acrescenta que a linguagem influencia também o comportamento, por transmitir um sistema de valores entranhados de tal forma na consciência que acabam por serem considerados naturais. Dessa forma, o discurso pode ser considerado, ao mesmo tempo, prática social cristalizada e modelador de uma visão de mundo (Fiorin, 2007:55-56). No que tange às vinculações sociais das narrativas midiáticas, Carvalho (2013:63) observou tratarem-se de indicadores das perspectivas éticas e morais de determinada sociedade em determinado momento.

As questões teóricas colocadas por Forin (ibidem) confirmam-se nas práticas discursivas jornalísticas. Veja-se, por exemplo, a matéria intitulada "Mulheres descartam vagas com apelo mais masculino", de Letícia Arcoverde, publicada no Jornal Valor, de 10 de julho de 2014. A autorarelata que a linguagem usada nos anúncios de emprego para determinados cargos influencia o perfil de candidatos que procuram por esses empregos. Palavras como "assertivo", "determinado", "analítico" e "agressivo" são menos atrativas para as mulheres, que dão preferência por vagas descritas com termos como "dedicado", "responsável" e "sociável". A matéria inclui um incentivo para que se faça uma avaliação das habilidades necessárias para a vaga de emprego de modo a evitar o uso de uma linguagem estereotipada, em vista da alegação de muitas empresas de que o número reduzido de mulheres em posições de comando deve-se à falta de candidatas disponíveis.

No entender de Thompson (2011), a relação entre linguagem e ideologia deve apoiar-se na análise sóciohistórica e na análise discursiva, para que se possa explorar as interconexões entre o significados das formas simbólicas e as relações de dominação. Para tanto, o autor propõe o desenvolvimento de uma reflexão crítica sobre a influência da mídia nas sociedades modernas.
Thompson (2011:426) acrescenta que é preciso treinar nossos olhos para ver as desigualdades da vida social, posto que nas sociedades modernas a diversidade e a diferença estão inseridas nas relações sociais que estão sistematicamente estruturadas de modo assimétrico.

Partindo-se, portanto,do pressuposto de que a informação veiculada na mídia refleteos valoresmorais e as tendências do mundo contemporâneo, o presente estudo tem como principal objetivo demonstraras formas de representação midiática da mulher, enfocando a linguagem verbal e a visual em revistasda área da aviação, nas quais buscam-se:

1. Os atributos linguísticos de referenciação à mulher em comparação ao homem;

2. Diferenças e similaridades na representação da mulher e do homem;

3. A fala da mulher.

\section{Metodologia}

Iniciou-se o presente estudo com a leitura de textos e imagens procedentes de revistas nacionais e estrangeiras impressas de 2010 a 2014 e/ou de matérias publicadas recentemente na internet. A coletânea de material para análise consistiu de 33 volumes de revistas impressas e 1 publicação on-line, todas da área da aviação. Entre as revistas analisadas incluem-se: Aero Magazine, Aeropolítica, Aerospace Engineering and Manufactoring, Asas, Avião em Revista, Avião Revue, Aviation Week $\mathcal{G}$ Space Technology, Bandeirante, CAT Magazine, Conexão Sipaer, Flap International, Flyer, Força Aérea, Frequência Livre, Ground Handling International, Guia Panrotas, ICAO Journal, Jane's Airport Review, Passenger Terminal World, Tecnologia $\&$ Defesa. Inclui-se adicionalmente uma revista em quadrinhos no tema sobre a aviação.

Na seção "Referências" somente foram listadas as publicações que trazem figuras e/ou matérias utilizadas no presente trabalho. Abaixo de cada imagem na seção "Resultados e discussão" está identificada a respectiva fonte. Na subseção "Figuras" faz-se a referenciação completa das figuras em separado das demais obras citadas no artigo. Atente-se para o fato de que as mesmas imagens podem ser encontradas em mais de uma fonte. Nesse caso, a escolha de uma ou outra fonte foi por mera questão de praticidade, priorizando-se as fontes de mais fácil acesso para as autoras no momento de redigir o presente artigo.

Procedeu-se a análise qualitativa dos textos e imagens escolhidos, buscando responder às seguintes questões:

1. De que forma a mulher está sendo representada nas imagens? 
2. Quais recursos linguísticos foram utilizados em referência à mulher nos textos escritos?

3. Quais são as possíveis implicações semânticas e contextuais do não dito?

Sempre que necessário, fez-se um recorte das imagens para que se pudesse evidenciar o aspecto de maior interesse para este estudo. As autoras esclarecem não haver em nenhuma hipótese a intenção de favorecer ou desfavorecer as instituições responsáveis por qualquer das imagens usadas no presente artigo.

Com o objetivo de melhor avaliar a situação da mulher na aviação nos dias de hoje, procederam-se adicionalmente entrevistas em separado com profissionais de três categorias diferentes: uma comissária, uma piloto e uma nomeada para cargo de agente administrativo que há 19 anos presta serviço no âmbito da aviação. Foi acordado com as entrevistadas não informar seus nomes, nem o local de trabalho, a fim de preservar sua identidade. A entrevista consistiu na aplicação de um questionário com as seguintes perguntas:

1. No exercício de sua profissão no âmbito da aviação você percebe alguma diferença de tratamento entre homens e mulheres?

2. O que você reivindicaria para melhorar o status da mulher?

3. Dados pessoais:

3.1 Tem formação superior?

3.2 Qual é a sua ambição de cargo e salário?

3.3 Numa escala de 0-10, em que posição você fica nos quesitos:

a) ambição e

b) proatividade?

Durante a entrevista, sempre que oportuno, aproveitou-se para esclarecer junto às entrevistadas algumas dúvidas relacionadas ao tema do presente trabalho.

Para maior clareza, subdividiu-se a seção "Resultados e Discussão" em três partes. Na primeira parte são discutidos os dados de textos verbais independente das figuras, a fim de delinear o perfil da mulher destacado na mídia. Na segunda parte são comentados os resultados das entrevistas. Finalmente, na terceira parte são apresentadas as imagens. Sempre que a interface texto verbal e imagem foi considerada relevante para o que se pretende mostrar no presente estudo, transcreveram-se parcialmente os textos verbais que acompanhavam essas imagens.

\section{Resultados e discussão}

\subsection{Perfil da mulher}

Nos segmentos de texto onde estão explicitadas algumas formas designativas em referência às mulheres da área da aviação foram encontrados diversos atributos de valor, como os mostrados nos Quadros 1 e 2, adiante.

Outros adjetivos podem ser inferidos dos textos, como os mostrados no Quadro 2.

Chama atenção a frequência de expressões de valor que se utilizam para referenciar as mulheres atuantes na aviação. Observa-se uma tendência a evidenciar as características excepcionais das (poucas) mulheres que se destacam na aviação. Frequentemente citamse no mesmo texto características que aparentemente contradizem o espírito audacioso, tais como delicada, discreta, tímida e tranquila. O próprio título da matéria referente à entrevista com a ex-diretora da ANAC ("A bela que não é fera!") gera uma ambiguidade que tanto pode ser entendida como enaltecedora da personalidade da entrevistada, como depreciadora de seu nível de entendimento dos assuntos da aviação.

A respeito da dualidade entre "pequenas e delicadas" e "grandes e fortes" mencionada por Stochero (2011), é discutível se para ser piloto é necessário ser grande e forte, mesmo em se tratando de pilotos do sexo masculino.

Outros comentários marcados estão presentes na própria fala das mulheres profissionais da aviação, como mostrado nos segmentos de texto a seguir.

\section{'Como é um voo feminino, o papo aqui dentro é de mulher. E do que mulher fala quando está sozinha?', brincou a comandante, quando questionada pela reportagem sobre o que conversaria nas alturas com a companheira. 'Agora que tenho uma filha, só falo de fraldas, cuidados com criança, mamadeiras. Mães fazem voos mais curtos, como ponte-aérea, para poder voltar para o lar mais rápido', diz Priscila. (Stochero, 2011)}

Essas são profissionais que aparentemente alcançaram sucesso. Parece, entretanto, não constituírem a regra geral, pois, no que tange ao envolvimento da mulher nas atividades domésticas, constata-se que a escolha da forma de conciliar a vida pessoal com a profissional muitas vezes impacta negativamente sobre as oportunidades de participação no mercado de trabalho. Conforme assinala Madalozzo et al. (2010:560-561), ainda não há a igualdade de condições para a entrada e a permanência de homens e mulheres no mercado de trabalho, pois elas cumprem uma segunda jornada extenuante e que, provavelmente, tem efeito em sua produtividade no mercado de trabalho e condições de saúde e bem estar. A autora advoga que, para a mulher competir em condições de igualdade de renda com o homem, é preciso adotar uma conduta que favoreça a sua capacidade de barganha na família, implicando uma menor participação no trabalho doméstico. 
Quadro 1 - Atributos de valor explicitados nos textos.

\begin{tabular}{|c|c|c|}
\hline Referenciação & Segmento & Fonte \\
\hline Audaciosa & {$[\ldots]$ a audaciosa Ada se tornou campeã $[\ldots]$} & Rodrigues \& Lima (2009, p. 1) \\
\hline Bela & Ela se mostra tímida, bela e econômica no verbo. & $\begin{array}{l}\text { A bela que não é fera! } \\
\text { Rev Frequência Livre }(2010, \text { p. } 35)\end{array}$ \\
\hline Corajosa & $\begin{array}{l}\text { [...] Determinadas e corajosas, elas passaram a ocupar, há pouco mais de } 20 \\
\text { anos, assentos garantidamente masculinos }[\ldots]\end{array}$ & Fay \& Oliveira $(2013$, p. 5) \\
\hline Delicada & $\begin{array}{l}{[\ldots] \text { Elas não são grandes nem fortes. São pequenas, discretas e delicadas. }} \\
\text { Não se esquecem do batom e, com unhas caprichosamente pintadas de } \\
\text { vermelho, seguram com mãos firmes um Boeing de até } 79 \text { toneladas. [...] }\end{array}$ & Stochero $(2011$, p. 1$)$ \\
\hline Determinada & $\begin{array}{l}\text { [...] Determinadas e corajosas, elas passaram a ocupar, há pouco mais de } 20 \\
\text { anos, assentos garantidamente masculinos }[\ldots]\end{array}$ & Fay \& Oliveira $(2013$, p. 5) \\
\hline Discreta & $\begin{array}{l}\text { [...] Discreta e persistente no preparo de seus voos, Ada [...] e } \\
{[\ldots] \text { Elas não são grandes nem fortes. São pequenas, discretas e delicadas. }} \\
\text { Não se esquecem do batom e, com unhas caprichosamente pintadas de } \\
\text { vermelho, seguram com mãos firmes um Boeing de até } 79 \text { toneladas. }[\ldots]\end{array}$ & $\begin{array}{l}\text { Rodrigues \& Lima }(2009, \text { p. 2) e } \\
\text { Stochero }(2011, \text { p. } 1)\end{array}$ \\
\hline Equilibrada & {$[\ldots]$ desde as primeiras aulas mostrou-se tranquila e equilibrada $[\ldots]$} & $\begin{array}{l}\text { Menina de } 14 \text { anos voa solo na inglaterra. } \\
\text { Rev Frequência Livre }(2014, \text { p. } 43)\end{array}$ \\
\hline Infernal & [...] a infernal aviadora iniciou sua instrução [...] & $\begin{array}{l}\text { Menina de } 14 \text { anos voa solo na Inglaterra. } \\
\text { Rev Frequência Livre }(2014, \text { p. } 43)\end{array}$ \\
\hline Inteligente & [...] Você é bonita, jovem e inteligente $[\ldots]$ & $\begin{array}{l}\text { A bela que não é fera!. } \\
\text { Rev Frequência Livre }(2010, \text { p. } 36)\end{array}$ \\
\hline Menina & {$[\ldots]$ a melhor das lições dessa menina volovelista de apenas 14 anos [...] } & $\begin{array}{l}\text { Menina de } 14 \text { anos voa solo na Inglaterra. } \\
\text { Rev Frequência Livre (2014, p. 43) }\end{array}$ \\
\hline Pequena & $\begin{array}{l}\text { [...] Elas não são grandes nem fortes. São pequenas, discretas e delicadas. } \\
\text { Não se esquecem do batom e, com unhas caprichosamente pintadas de } \\
\text { vermelho, seguram com mãos firmes um Boeing de até } 79 \text { toneladas. [...] }\end{array}$ & Stochero $(2011$, p. 1) \\
\hline Persistente & [...] Discreta e persistente no preparo de seus voos, Ada [...] & Rodrigues \& Lima (2009, p. 2) \\
\hline Talentosa & [...] o feito da talentosa Zoe Mallam [...] & $\begin{array}{l}\text { Menina de } 14 \text { anos voa solo na Inglaterra. } \\
\text { Rev Frequência Livre }(2014, \text { p. } 43)\end{array}$ \\
\hline Tímida & Ela se mostra tímida, bela e econômica no verbo. & $\begin{array}{l}\text { A bela que não é fera! } \\
\text { Rev Frequência Livre }(2010, \text { p. 35) }\end{array}$ \\
\hline Tranquila & {$[\ldots]$ desde as primeiras aulas mostrou-se tranquila e equilibrada $[\ldots]$} & $\begin{array}{l}\text { Menina de } 14 \text { anos voa solo na Inglaterra. } \\
\text { Rev Frequência Livre (2014, p. 43) }\end{array}$ \\
\hline Valorosa & [...] A valorosa aviadora $[\ldots]$ & Rodrigues \& Lima (2009, p. 5) \\
\hline
\end{tabular}

Quadro 2 - Atributos de valor inferidos dos textos.

\begin{tabular}{|c|c|c|}
\hline Adjetivo & Segmento & Fonte \\
\hline $\begin{array}{l}\text { Arrojada } \\
\text { (implícito) }\end{array}$ & $\begin{array}{l}{[\ldots] \text { conseguiu mostrar pelas Américas o valor, o arrojo, o espírito patriótico do }} \\
\text { piloto brasileiro. [...] }\end{array}$ & Rodrigues \& Lima (2009, p. 4) \\
\hline $\begin{array}{l}\text { Aventureira } \\
\text { (implícito) }\end{array}$ & $\begin{array}{l}{[\ldots] \text { com seu espírito aventureiro, a aviadora }[\ldots] \text { só encerrou sua série de }} \\
\text { grandes viagens }[\ldots]\end{array}$ & Rodrigues \& Lima (2009, p. 3) \\
\hline $\begin{array}{l}\text { Corajosa } \\
\text { (implícito) }\end{array}$ & [...] Prova de coragem e arrojo. [...] & Rodrigues \& Lima (2009, p. 4) \\
\hline $\begin{array}{l}\text { Independente } \\
\text { (implícito) }\end{array}$ & $\begin{array}{l}\text { [...] Ada Rogato não contou com auxilio de nenhum piloto nacional ou estrangeiro } \\
{[\ldots] \text { e o que é mais notável, viajando só e sem auxílio de qualquer piloto. [...] }}\end{array}$ & Rodrigues \& Lima (2009, p. 4) \\
\hline
\end{tabular}

\subsection{Nossas entrevistadas}

Por ser uma amostra pequena, a presente entrevista não pretende ser representativa das mulheres do mundo todo, nem tampouco das brasileiras de um modo geral. Tratam-se de depoimentos de trêsprofissionais do âmbito da aviação.
Nossas entrevistadas invariavelmente relatam ter menor ambição, maior proatividade. A julgar por seus cargos e por sua formação de nível superior, vê-se que são pessoas altamente preparadas, mas aparentemente a questão salarial não parece ser tão relevante. Uma justificativa para a baixa ambição, segundo a agente administrativa, deve-se ao fato dela valorizar o 
convívio com a família e os amigos, com quem prefere compartilhar o seu tempo, embora o trabalho também seja importante. Ressalte-se que a preocupação com a família é uma característica recorrente nas entrevistas com as profissionais da aviação divulgadas na mídia, conforme apontado por Moralez (2014: 70-2).

A piloto e a comissária concordam que o tratamento dado às mulheres em relação aos homens no seu campo de atividade é diferenciado, estando a mulher em clara desvantagem quanto às oportunidades de acesso aos postos mais privilegiados. A agente administrativa esclarece que não se trata de algo pessoal, mas as diferenças dizem respeito principalmente ao domínio profissional. Nesse sentido, relatam de forma contraditória a questão da mulher que está no poder apoiar ou não as colegas. A piloto e a agente administrativa informam que as mulheres não são unidas, enquanto a comissária alegater recebido pleno apoio de sua superiore enfatiza que a mulher tende a ser tratada de acordo com a atitude adotada e com o valor que atribui a si própria.

Quanto ao que gostariam de reivindicar para melhorar o status da mulher, foi destacada a importância do tratamento igualitário na educação de meninos e meninas, de maior equilíbrio na distribuição de cargos entre homens e mulheres, e a necessidade da aquisição de uma base sólida de conhecimento e de maior ousadia para emitir opinião fundamentada e para argumentar.

\subsection{Análise de imagense interface com o texto verbal}

\subsubsection{Pilotos}

Nas fotos de mulheres no cockpit, tipicamente a mulher é retratada sorrindo e em rosto frontal, claramente posando para o fotógrafo, como na Figura 1.2. Em contraste, os pilotos do sexo masculino geralmente aparecem de costas ou de perfil, sérios e engajados na função Figura 1.1). As profissionais da aviação (piloto, comissária e agente administativo) entrevistadas no presente estudo foram solicitadas a comentar a respeito dessa particularidade. A piloto e a agente administrativo atribuem o sorriso presente nas fotos das mulheres no cockpit à alegria de terem chegado aonde chegaram, decorrente da conquista realizada com tanto sacrifício, e da evidente satisfação de quem gosta do que faz. A comissária, por sua vez, supõe que, no caso das comissárias, o sorriso faz parte do perfil desejável, pois estas devem ser capazes de cativar e tranquilizar os passageiros, devem ser amáveis e extrovertidas ao lidar com o público, sendo que frequentemente ouve-se a frase clichê: "o comissário é o cartão de visita da empresa".
Nas Figuras 1.3 e 1.4 são mostradas as mãos dos pilotos. Note-se que às mãos do homem não foi dado nenhum zoom, estão ocupadas, enquanto a mão da mulher é mostrada com foco nas unhas pintadas. De fato, são comuns as matérias que dão especial ênfase ao fato de que as mulheres da aviação apesar de usarem batom e terem as unhas pintadas, "seguram com mãos firmes um Boeing de até 79 toneladas" (Stochero, 2011).

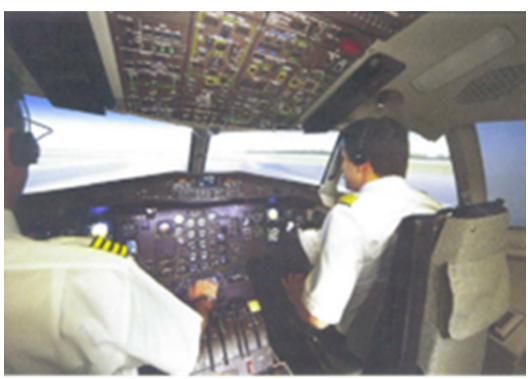

Figura 1.1

Fonte: Icao Journa/ 3(1), 2013: 44

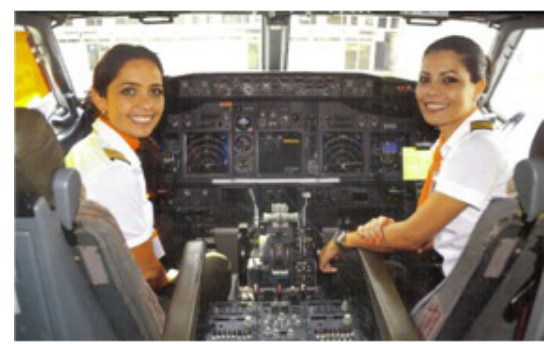

Figura 1.2

Fonte: Moralez, 2014: 71

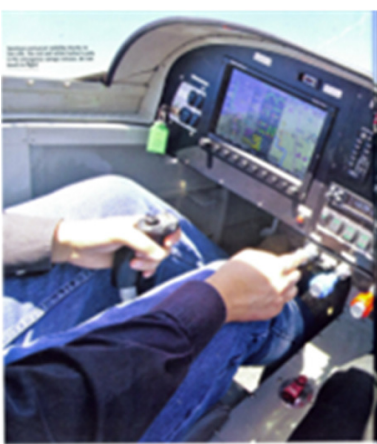

Figura 1.3

Fonte: Flyer s/n, 2014: 32

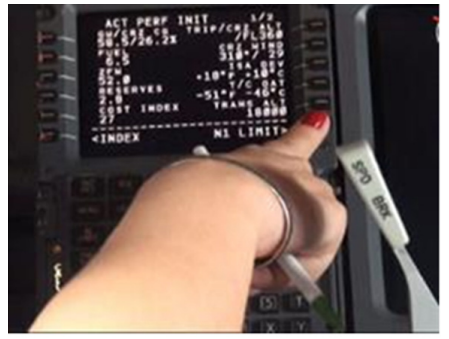

Figura 1.4

Fonte: Stochero, 2011 


\subsubsection{Treinamento}

Embora a mulher apareça frequentemente associada à área educacional, seja como aprendiz, seja como instrutora nos cursos e centros de treinamento (Figuras 2.1, 2.2, 2.4 e 2.5), nos anúncios de cursos para pilotos e nas matérias sobre treinamento e capacitação do pessoal da aviação vê-se que o apelo é maior para o públicoalvo masculino. Observou-se no presente estudo que nos anúncios sobre cursos profissionalizantes de outros segmentos da área da aviação, tais como atendimento a passageiro, Segurança da Aviação Civil (AVSEC), cursos na área de rampa, operações ou relacionados à carga aérea, a presença da mulher é mais comum. No entanto, as imagens 2.1, 2.2 e 2.3 evidenciam a presença minoritária de mulheres nos anúncios e matérias sobre cursos para pilotos.

Nota-se, além disso, o uso diferenciado da linguagem midiática feminina em relação aos anúncios masculinos. A linguagem feminina inclui frequentemente, além do sorriso, o uso da retórica como recurso persuasivo, com a promessa de satisfazer as necessidades do cliente, e de termos como "flexibilidade" e "eficiência". Na foto 2.5 uma mulher pilota uma aeronave e, como de costume, vira para a câmera e sorri. Diferente dos textos que acompanham os demais anúncios, esse anúncio, pouco informativo na questão do que será abordado no curso, inclui perguntas retóricas e promete satisfazer o aprendiz. Transcreveu-se o texto parcialmente:

[nome da instituição de ensino] offers you the training you need, where you need it. We can provide the pilots you require [...] products and services that meet your training needs [...] ensuring that you get the flexibility and efficiency you want. As customer, isn't that what you expect? Let us give you what you want $[. .$.$] .$

Compare-se com o texto da Figura 2.6:

O futuro é o reflexo do que você faz hoje. Seja piloto. Veja o mundo de cima.

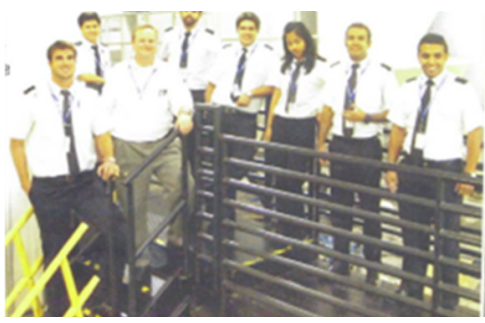

Figura 2.1

Fonte: Icao Journa/ 3(1), 2013: 21

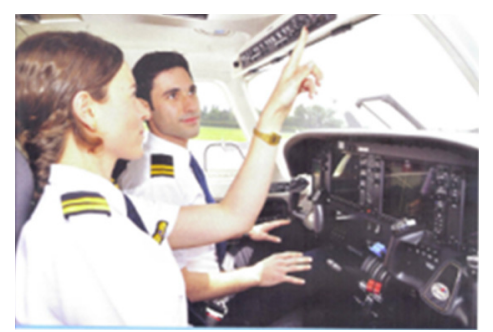

Figura 2.4

Fonte: Flyer 9, 2014: 23.

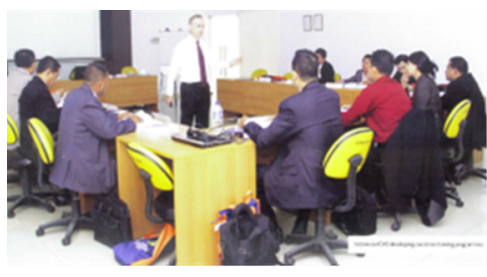

Figura 2.2

Fonte: Icao Journal 3(1), 2013: 31.

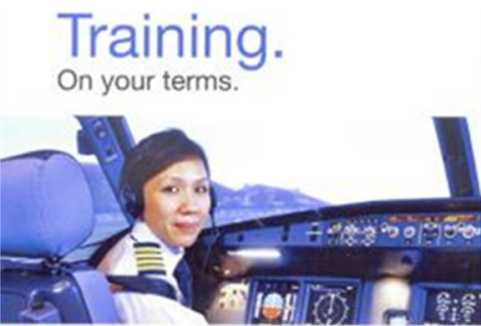

Figura 2.5

Fonte: Cat Magazine 24(6), 2013: contracapa.

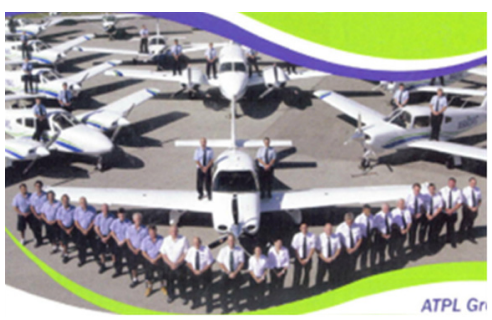

Figura 2.3

Fonte: Flyer 9, 2014: 78

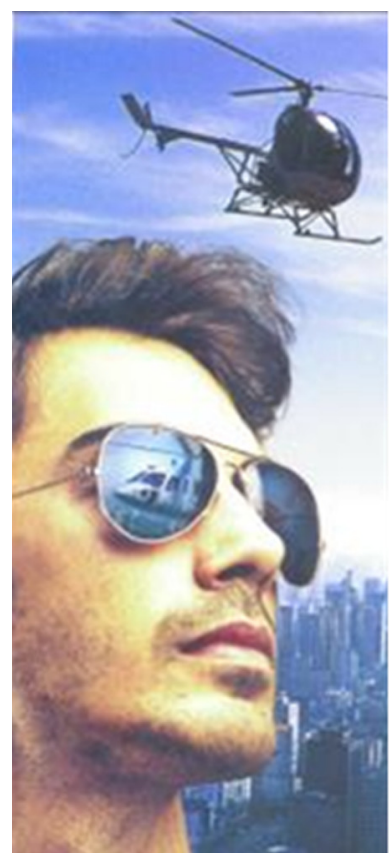


Seguem informações sobre os cursos ministrados no Centro de Instrução. Ressalte-se que nos óculos do rapaz dessa foto há o reflexo de um helicóptero diferente do que aparece na figura, como se ele já estivesse se vendo lá, pilotando, realizando o seu sonho. Além de mais informativa, a propaganda da Figura 2.6 alimenta a ambição no candidato em potencial. Embora tenhamos encontrado algumas matérias que documentam a existência de mulheres piloto de helicóptero, duas das quais podem ser encontradas no volume da Revista Tecnologia $\mathbb{E}$ Defesa dedicado ao centenário da aviação militar de São Paulo, anúncios de cursos para piloto de helicóptero dirigidos ao público feminino praticamente inexistem na nossa amostra.

\subsubsection{Usuários}

Diferente do homem, que quase sempre é retratado em trajesocial (Figuras 3.1 e 3.3), a mulher usuária da aviação, com raras exceções, é retratada em traje de passeio, como passageira de classe executiva, usufruindo dos serviços de bordo (Figura 3.2). Nos aeroportos, frequentemente vê-se a mulher levando uma criança de colo ou acompanhada de um homem, como mostrado na Figura 3.4. Numa época em que muitas mulheres, tal como os homens, viajam sozinhas a trabalho e que a maioria opta pela classe econômica, pode-se questionar o porquêdessas tendências nos retratos da mídia.

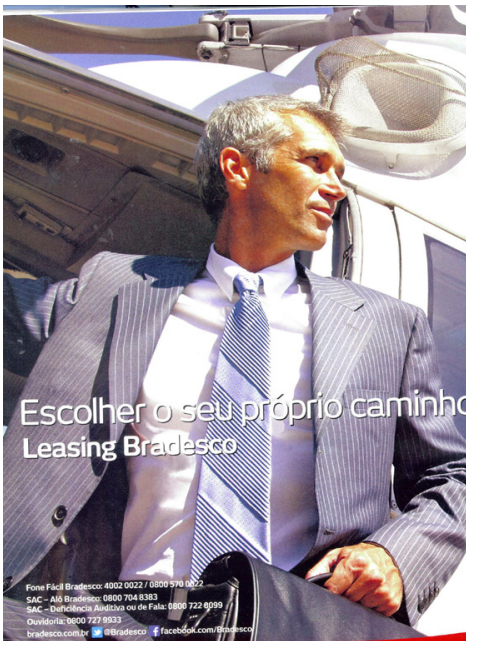

Figura 3.1

Fonte: Flap Internacional 501, 2014: 70

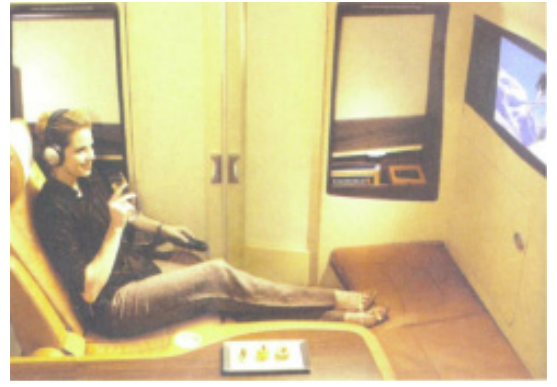

Figura 3.2

Fonte: Flap Internacional 458, 2010: 70.

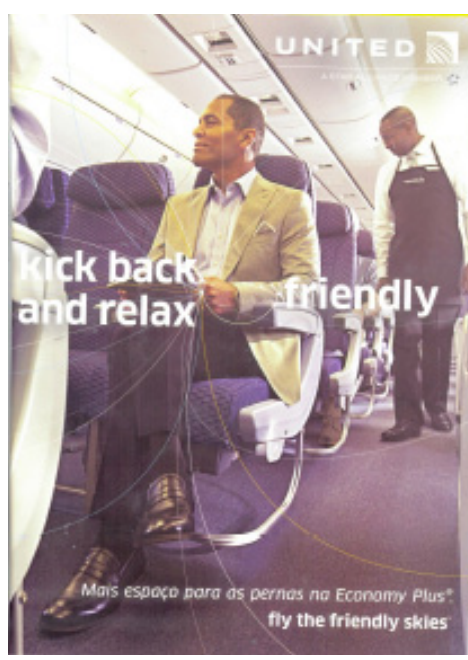

Figura 3.3

Fonte: Avião Revue 179, 2014: 99.

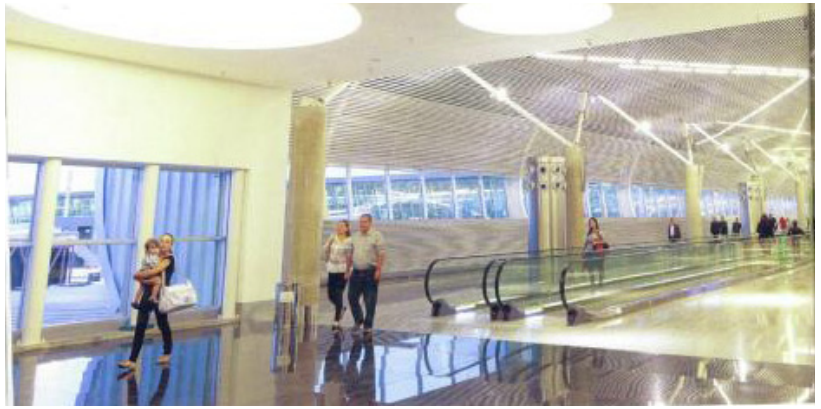

Figura 3.4

Fonte: Aero Magazine 242, 2014: 40 


\subsubsection{Pin-ups, nose art e marketing}

"Pin-up" é um termo inglês que significa "pendurar" em referência ao fato dessas imagens provocantes terem sido estampadas nos pôsteres e calendários que ficavam pendurados nas paredes de oficinas mecânicas dos anos 30 a 50 (Santos, 2014). O uso da imagem da mulher sensual associado à aviação data da década de 40, com as pin-ups pintadas na fuselagem dos bombardeiros usados na Segunda Guerra Mundial. Ainda hoje encontram-se pin-ups nas revistas da aviação, como mostrado nas Figuras 4.1, 4.3 e 4.5. As Figuras 4.1 e 4.3 foram extraídas da mesma revista. Nessa revista há uma pin-up de página inteira (Figura 4.3) e diversas pin-ups de pequeno tamanho, posicionadas no alto à esquerda das páginas, como a mostrada na Figura 4.1.

A Figura 4.2 trata-se de uma pinturada cantora Ivete Sangalo aplicada no nariz de uma aeronave P-3AM da Força Aérea Brasileira. Para melhor visualização, na Figura 4.4 é ampliado o detalhe no alto à esquerda da Figura 4.2. Apesar de mais comportada, pode-se dizer que a nose art da cantora é usada com a mesma finalidade das pin-ups de "motivar os esquadrões militares" Moralez (2014:40-41). A Figura 4.3 é uma ilustração da matéria sobre o artista Tomas Pietro, conhecido também por seus desenhos de aeronaves, publicados em revistas da aviação, cujo leitor potencial é predominantemente masculino. A loira que aparece na página serviu de tema para um cartão de Natal e não foi pintada na fuselagem de nenhuma aeronave. Mas certamente faz alusão às famosas pin-up girls e sua presença destacada na revista serve igualmente ao propósito de atrair o público leitor masculino.

O corpo feminino é usado para vender não apenas revistas da aviação, mas também de acessórios de aeronaves, como no anúncio da Figura 4.6, sobre o sistema de winglet, na qual se lê: "Elegante e Estiloso. Como você". Conforme assinala Citelli (2004:93-95), a prática da persuasão pelo uso de imagens e do discurso verbal não é um mal em si mesmo, posto que, para atingir seu fim, é necessário que o próprio leitor se deixe persuadir. Segundo o mesmo autor, a atitude persuasiva só é má quando se torna a única manifestação de cultura e não apresenta resultados socialmente positivos. Nesse contexto, cabe perguntar se a mulher representada na mídia contemporânea corresponde à pluralidade de formas com que ela atua no meio aeronáutico ou se se limita a calcar os antigos e desgastados estereótipos.

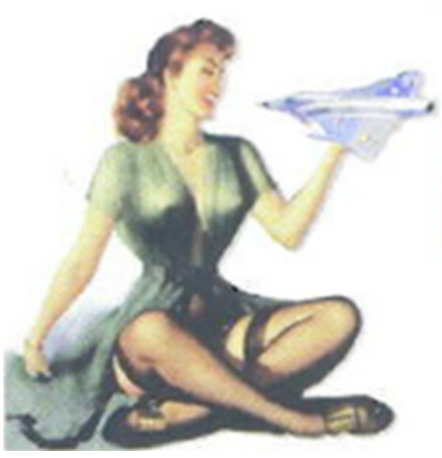

Figura 4.1

Fonte: Asas 77, 2014: 92.

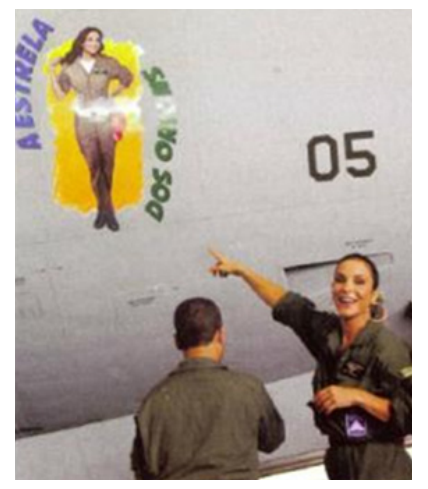

Figura 4.4

Fonte: Asas 79, 2014: 41.

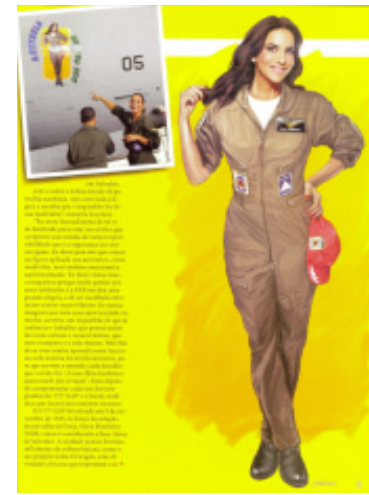

Figura 4.2

Fonte: Asas 79, 2014: 41.

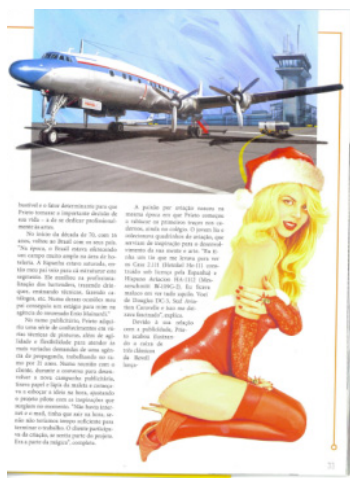

Figura 4.5

Fonte: Asas 77, 2014: 33.

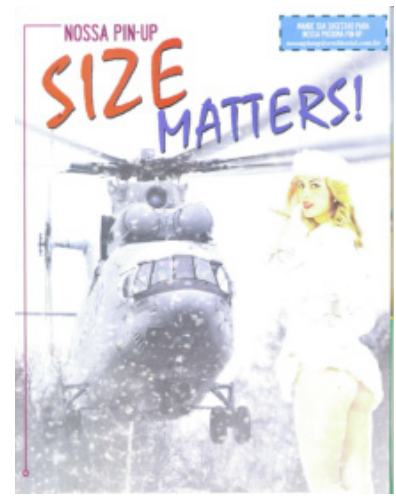

Figura 4.3

Fonte: Asas ํo 77, 2014:98.

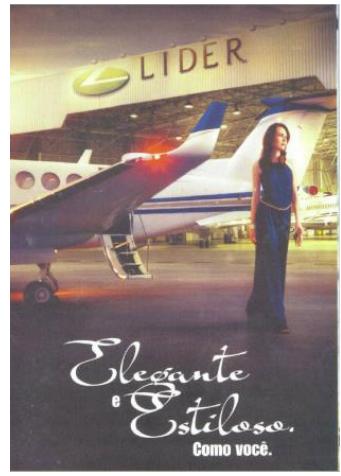

Figura 4.6

Fonte: Aero Magazine 242, 2014: 55. 


\subsubsection{Crianças}

No que tange ao incentivo dado às crianças para que optem pela aviação, as revistas estrangeiras e as brasileiras tratam o assunto de forma diferente. Embora os meninos apareçam com maior freqüência em ambas (Figuras 5.1, 5.3, 5.5 e 5.6), nas revistas estrangeiras é possível encontrar imagens e textos encorajadores para as meninas. Por exemplo, a menina da Figura 5.4 está sentada dentro de uma aeronave em exposição num aeroporto durante a comemoração do vigésimo aniversário da revista Flyer, e ao lado da fotohá uma legenda na qual se lê: when Elizabeth grows up, she'll be flying her Dad's electric racer. Na Figura 5.1, embora apareçam duas meninas, elas encontram-se sentadas, passivamente obsevando o menino "pilotar" o avião de papel.

Na maioria das revistas de aviação brasileiras quase sempre se vê foto de meninos nas imagens de apelo para pilotos. Curiosamente, a protagonista (menina) de uma estória em quadrinhos, que sonha em pilotar aviões, ora ocupa o posto de comandante, ora encontra-se vestida de comissária, na mesma revista. Ressalte-se que a revista foi uma realização da Força Aérea Brasileira, do Centro de Investigação e Prevenção de Acidentes Aeronáuticos (CENIPA) e da ANAC, entre outros, e foi distribuída gratuitamente na comemoração do Dia do Servidor Público na ANAC em 2013.

Outras vezes a revista brasileira divulga fotos de crianças prodígio estrangeiras, nem tanto pelo feito dessas crianças, mas principalmente como recurso para pleitearem algo, como é o caso ilustrado pela figura 5.2, de uma "menina" europeia de 14 anos, que ilustra uma crítica à legislação brasileira referente à idade exigida para se começar a pilotar, dando a entender que até uma adolescente pode fazer. No layout da página da Figura 5.2, note-se o pouco destaque dado à aviadora pela posição no canto inferior à direita da página e tamanho reduzido da foto da adolescente, em contraste com a foto do(a) bebê na metade superior.

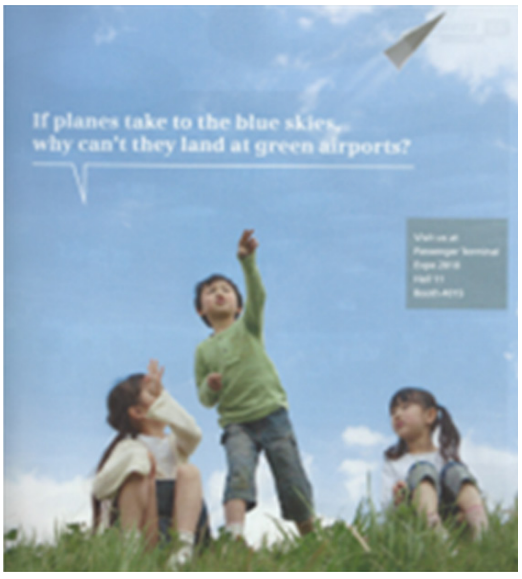

Figura 5.1

Fonte: Passenger Terminal World s/n, 2010: 41.

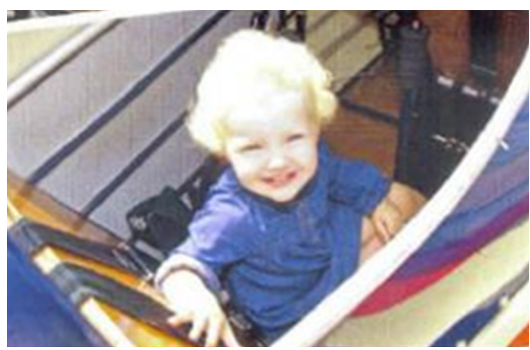

Figura 5.4

Fonte: Flyer 9, 2014: 12

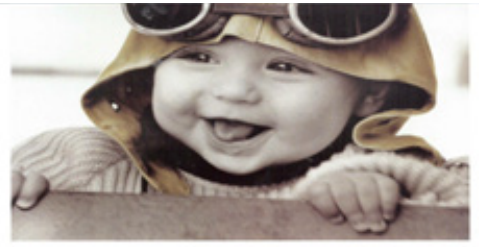

Menina de 14 anos voa solo na Inglaterra

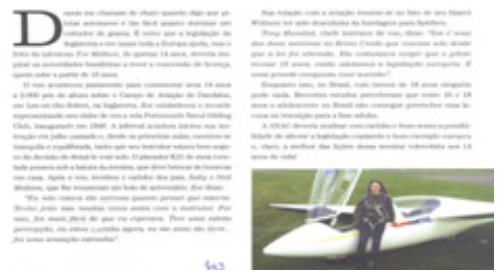

Figura 5.2

Fonte: Frequência Livre 74, 2014: 43.

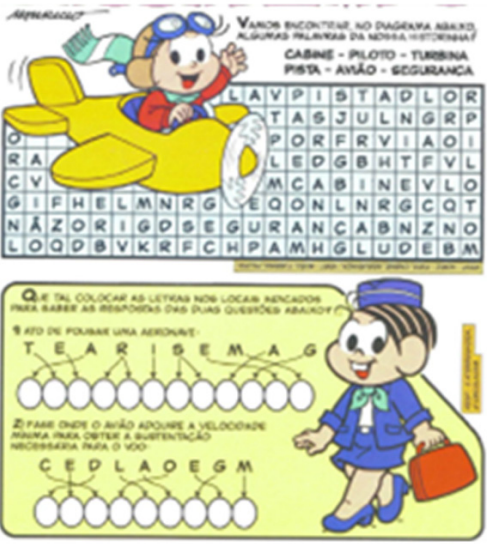

Figura 5.5

Fonte: Sousa, ed. especial, 2013: verso da capa.

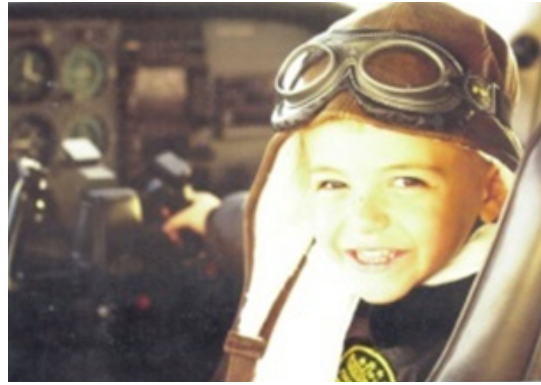

Figura 5.3

Fonte: Icao Journal 3(1), 2013: 4.

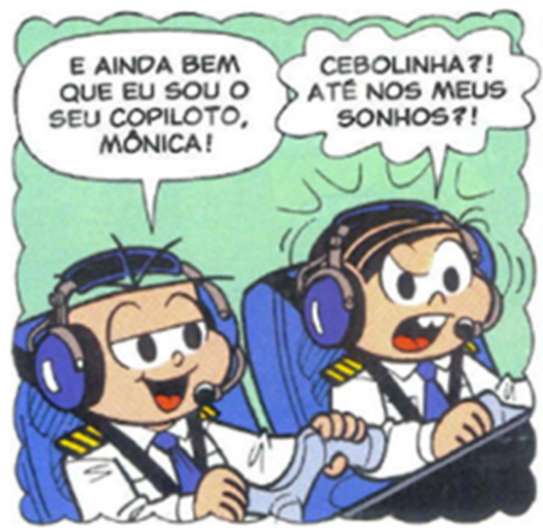

Figura 5.6

Fonte: Sousa, ed. especial, 2013: 7. 


\section{Considerações finais}

Por meio do presente estudo evidencia-se a existência de comportamentos sociais estereotipados divulgados pela mídia que podem estar refletindo e, ao mesmo tempo, consolidando a situação de desequilíbrio entre os gêneros na área da aviação. Nesse sentido, as autoras ecoam as falas de Abramo (2007) e Lehman (2014) sobre a necessidade de se construir uma cultura de inclusão e de valorização da mulher no mercado, por meio da implementação de novas formas de organização familiar e do trabalho público e privado. Particularmente desejável é o incentivo à capacitação da mulher nas áreas em que há falta de recursos humanos para atender a crescente demanda de mercado e onde a participação masculina vem sofrendo oscilações a nível global, como na formação de pilotos de todas as modalidades.

No que tange à apreensão dos significados veiculados na representação midiática da mulher na aviação, as autoras concordam com Buitoni (2011) sobre o dever de exercitarmos outros olhares sobre a realidade que nos circunda, diferentes da mídia convencional. No discurso, são necessárias mudanças semânticas e linguísticas que favoreçam a participação da mulher em uma gama mais ampla de profissões na área da aviação. A fotografia certamente pode continuar a ser usada como instrumento de arte, mas deve também retratar uma variabilidade maior de situações e auxiliar no resgate da dignidade e da seriedade requeridas das profissionais da indústria aeronáutica que planejam alçar voos mais altos e pilotar suas carreiras, por sua própria competência e determinação.

\section{Referências}

A BELA QUE NÃO É FERA! Entrevista com Solange Vieira. Revista Frequência Livre, São Paulo, n. 51, p. 34-38, abr. 2010.

ABRAMO, L. W. A inserção da mulher no mercado de trabalho: uma força de trabalho secundária? Tese (Doutorado em Sociologia) - Universidade de São Paulo, São Paulo, 2007.

ALMEIDA, S. R. G. Gênero, identidade, diferença. Revista Aletria, p. 90-97, 2002. Disponível em: < http://www.letrs.ufmg. br/poslit>. Acesso em: 26 ago. 2014.

A MULHER NA AVIAÇÃO. Disponível em: < http://www. setetaxiaereo.com.br/noticia/a-mulher-na-aviacao >. Acesso em: 11 mar. 2014.

ARCOVERDE, L. Mulheres descartam vagas com apelo mais masculino. Jomal Valor, 10 jul. 2014. Seção EU \& Carreira. p. D3.

ATWOOD, M. Good bones. Toronto: M\&S, 1987.

BARBOZA, M. Q. Mesmo no topo, elas ainda ganham menos. Revista Isto é, São Paulo, ano 38, n. 2311, p. 62-63, 2014.

BUITONI, D. S. Fotografia e jornalismo: a informação pela imagem. São Paulo: Saraiva, 2011.
BUTLER, J. P. Problemas de gênero: feminismo e subversão da identidade. Tradução de Renato Aguiar. Rio de Janeiro: Civilização Brasileira, 2003. 236 p.

CARNEY, T.; FLANAGAN, D. The next generation of aviation professionals. ICAO Training Report, v. 3, n. 1, jun.-jul. 2013.

CARVALHO, C. A. Apontamentos teóricos e metodológicos para compreender as vinculações sociais das narrativas. In: LEAL, B. S.; CARVALHO, C. A. (Org.). Narrativas e poéticas midiáticas: estudos e perspectivas. São Paulo: Intermeios, 2013. p. 49-65.

CITELLI, A. Linguagem e persuasão. 16. ed. São Paulo: Ática, 2004.

CONTROLADORIA GERAL DA UNIÃO. Portal da Transparência. Cargos Comissionados da Agência Nacional de Aviação Civil. Disponível em: <http://www.portaldatransparencia. gov.br >. Acesso em: 11 ago. 2014.

FAY, C. M.; OLIVEIRA, G. G. As mulheres na aviação brasileira. In: SEMINÁRIO INTERNACIONAL FAZENDO GÊNERO, 10., 2013, Florianópolis. Anais eletrônicos... Florianópolis, 2013. p. 1-9. Disponível em: <http://www.fazendogenero.ufsc.br>. Acesso em: 24 jul. 2014.

FERRO, F.; MILESKI, A. M.; MAIA, P. (Ed.) Chegam as mulheres. Revista Tecnologia E̊ Defesa, edição especial, p. 66-67, 2013.

FIORIN, J. L. Linguagem e ideologia. São Paulo: Ática, 2007.

IMPRENSA NACIONAL. Disponível em: < http://portal. in.gov.br >. Acesso em: 11 ago. 2014.

LEHMAN, C. A culture of inclusion. Editorial comment. CAT magazine, v. 25, n. 2, p. 5, 2014.

MADALOZZO, R.; MARTINS, S. R.; SHIRATORI, L. Participação no mercado de trabalho e no trabalho doméstico: homens e mulheres têm condições iguais? Revista Estudos Feministas, Florianópolis, v. 18, n. 2, p. 547-566, maio-ago. 2010.

MORAlEZ, J. P. Estrela dos Orions. Revista Asas, São Paulo, n. 79, p. 40-41, jun.-jul. 2014.

MORAlEZ, J. P. Tomas Prieto. Seção Academia de Artes. Revista Asas, São Paulo, n. 77, ano XIII, p. 33, fev-mar 2014.

MORALEZ, J. P. Tripulação, gênero feminino. Revista Asas, São Paulo, n. 79, p. 70-72, jun.-jul. 2014

PENG, R. Cresce número de mulheres que se habilita a pilotar avião. Disponível em: < http://www.paranashop.com.br >. Acesso em: 23 mar 2010

PROBST, E. R.A Evolução da mulher no mercado de trabalho. Revista do Instituto Catarinense de Pós-Graduação, p. 1-8, jan.-jun. 2003. Disponível em: <www.posuniasselvi.com.br/artigos>. Acesso em: 27 ago. 2014.

RODRIGUES, C. Butler e a desconstrução do gênero. Revista Estudos Feministas, Florianópolis, v. 13, n. 1, jan.-abr. 2005.

RODRIGUES, L. E. M. J.; LIMA, C. C. Mulheres Aviadoras: o pioneirismo de Ada Rogato e seus feitos históricos na aviação brasileira. Revista Eletrônica Aero Design Magazine, v. 1, n. 1, 2009.

SALIH, S. Judith Butler e a Teoria Queer. Tradução de Guacira Lopes Louro. Belo Horizonte: Autêntica, 2013.

SANTOS, C. A força e feminilidade das pin-ups ao longo da história. Disponível em: < http://lounge.obviousmag.org/letras pulsantes >. Acesso em: 3 ago. 2014

STOCHERO, T. Mulheres avançam no mercado da aviação $e$ chegam a comando de voo. Disponível em: <www.globo.com>. Acesso em: 24 out. 2011. 
THOMPSON, J. B. Ideologia e cultura moderna: teoria social crítica na era dos meios de comunicação de massa. Petrópolis, Vozes, 2011.

TRINDADE, E. A publicidade e a modernidade-mundo: as representações de pessoa, espaço e tempo. In: BARBOSA, I. S. (Org.). Os sentidos da publicidade: estudos interdisciplinares. São Paulo: Pioneira Thomson Learning, 2005. p. 81-95.

WILSON, V.; MARTELOTTA, M. E. Arbitrariedade e iconicidade. In: MARTELOTTA, M. E. (Org.). Manual de linguística. São Paulo: Contexto, 2013. p. 71-85.

ZWERDLING, R. Brasileiras pioneiras. Aero Magazine, São Paulo, ano 20, n. 229, 2013.

\section{Figuras}

1.1 INTERNATIONAL CIVIL AVIATION ORGANIZATION. The value of debriefing stations for the full flight simulator. Icao Journal, Montreal, v. 3, n. 1, p. 44, 2013.

1.2 MORAlEZ, J. P. Tripulação, gênero feminino. Revista Asas, São Paulo, n. 79, p 71, jun.-jul. 2014.

1.3 HICKS, E. Van's RV-14A. Flyer, Bath, UK: Seager, n. 9, p. 32, Aug. 2014.

1.4 STOCHERO, T. Mulheres avançam no mercado da aviação e chegam a comando de voo. Disponível em: <www.globo. com>. Acesso em: 24 out. 2011.

2.1 PANAM INTERNATIONAL FLIGHT ACADEMY. We create airline pilots. Icao Journal, Montreal, v. 3, n. 1, p. 21, 2013.

2.2 INTERNATIONAL CIVIL AVIATION ORGANIZATION. State profile Indonesia. Icao Journal, Montreal, v. 3, n. 1, p. 31, 2013.

2.3 NAPLES AIR CENTER. Realize your dream. Flyer, Bath, UK: Seager, n. 9, p. 78, Aug. 2014.

2.4 CAE Oxford Aviation Academy. Discover your path to an airline pilot career. Flyer, Bath, UK: Seager, n. 9, p. 23, Aug. 2014.

2.5 CAE. Training on your terms. Cat Magazine: The Journal for Civil Aviation Training, Hampshire, UK: Halldale Media Group, v. 24, n. 6, back cover, 2013.

2.6 EDRA Aeronáutica. O futuro é o reflexo do que você faz hoje. Avião Revue, São Paulo: Key, ano 14, n. 179, p. 9, ago. 2014.

3.1 BRADESCO. Escolher o seu próprio caminho é tudo de BRA. Leasing Bradesco. Revista Flap Internacional, São Paulo: Grupo Editorial Spagat, ano 51, n. 501, p. 70, jun. 2014.
3.2 KLOTZEL, E. O glamour do A380. Revista Flap Internacional, São Paulo: Grupo Editorial Spagat, ano 48, n. 458 , p. $70,2010$.

3.3 UNITED. Kick back and relax friendly. Avião Revue, São Paulo: Key, ano 14, n. 177, p. 99, jun. 2014.

3.4 UBIRATAN, E. O legado da Copa. Revista Aero Magazine, São Paulo: Inner, ano 21, n. 242, p. 40, 2014.

4.1 MORALEZ, J. P. Um museu ao alcance das mãos. Revista Asas, São Paulo, ano XIII, n. 77, p. 92, fev.-mar. 2014.

4.2 MORALEZ, J.P. Estrela dos Orions. Revista Asas, São Paulo, n. 79, p. 41, jun.-jul. 2014.

4.3 BILBAO, V. Nossa pin-up. Revista Asas, São Paulo, ano XIII, n. 77, p. 98, fev.-mar 2014.

4.4 MORAlEZ, J. P. Estrela dos Orions. Revista Asas, São Paulo, ano XIII, n. 79, p. 41, jun.-jul. 2014.

4.5 MORALEZ, J. P. Tomas Prieto. Seção Academia de Artes. Revista Asas, São Paulo, ano XIII, n. 77, p. 33, fev.-mar. 2014.

4.6 BRL Aerospace. Elegante e estiloso. Como você. Revista Aero Magazine, São Paulo: Inner, ano 21, n. 242, p. 55, 2014.

5.1 SIEMENS. Innovative products and solutions lead to energy-efficient and environmentally friendly airports. Passenger Terminal World, Dorking, UK: UKIP Media \& Events, s/n, p. 41, Mar. 2010.

5.2 MENINA DE 14 ANOS VOA SOLO NA INGLATERRA. Revista Frequência Livre, São Paulo, n. 74, p. 43, abr. 2014.

5.3 INTERNATIONAL CIVIL AVIATION ORGANIZATION. The next generation of aviation professionals. Icao Journal, Montreal, v. 3, n. 1, p. 4, 2013.

5.4 FLYER FLY-IN. Highlights from Flyer's 20th anniversary fly-in at Gloucestershire Airport. Flyer, Bath, UK: Seager, n. 9, p. 12, Aug. 2014

5.5 SOUSA, M. Turma da Mônica e a segurança de voo. Revista Turma da Mônica, Barueri, edição especial, verso da capa, 2013.

5.6 SOUSA, M. Turma da Mônica e a segurança de voo. Revista Turma da Mônica, Barueri, edição especial, p. 7, 2013.

Endereço para correspondência:

Patrícia Almeida de Rezende

Rua Gal. Góis Monteiro, 8

22290-080 Botafogo, RJ, Brasi

Tel.: (21) 2275-5925

<parezende@gmail.com> 